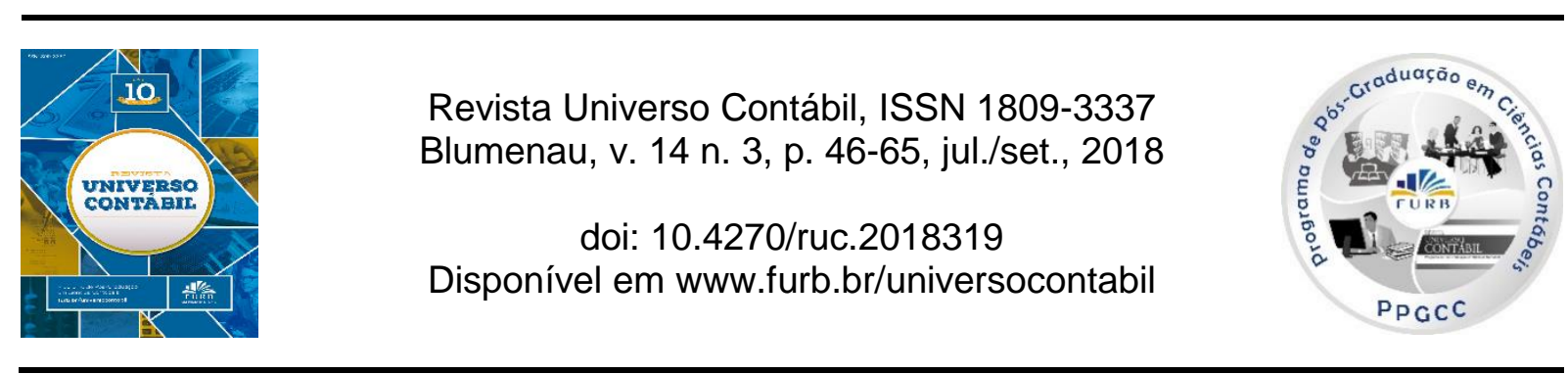

\title{
RELEVÂNCIA DA INFORMAÇÃO CONTÁBIL: ESTUDO DE EVENTOS NO SETOR DE PETRÓLEO E GÁS1
}

\section{VALUE RELEVANCE OF ACCOUNTING INFORMATION: EVENT STUDY IN THE OIL AND GAS INDUSTRY}

\section{RELEVANCIA DE LA INFORMACIÓN CONTABLE: ESTUDIO DE EVENTOS EN EL SECTOR DE PETRÓLEO Y GAS}

\author{
Raphael da Fonseca \\ Mestre em Ciências Contábeis pela Universidade Federal do Rio de Janeiro \\ Endereço: Rua Teixeira Júnior, 222. São Cristóvão \\ CEP: 20921-405 - Rio de Janeiro - RJ - Brasil \\ E-mail: raphafonseca@hotmail.com \\ Telefone: (21) 99611-6457
}

José Augusto Veiga da Costa Marques Pós-Doutor em Controladoria e Contabilidade pela Universidade de São Paulo Professor do PPG em Ciências Contábeis da Universidade Federal do Rio de Janeiro Endereço: Avenida Pasteur, no 250, Sala 251, Urca CEP: 22290-240 - Rio de Janeiro - RJ - Brasil

E-mail: joselaura@uol.com.br Telefone: (21) 97926-7143

Odilanei Morais dos Santos Doutor em Controladoria e Contabilidade pela Universidade de São Paulo Professor do PPG em Ciências Contábeis da Universidade Federal do Rio de Janeiro Endereço: Rua Conde de Irajá, 420 apto 907, Botafogo CEP: 22.271-020 - Rio de Janeiro - RJ - Brasil E-mail: odilaneisantos@terra.com.br Telefone: (21) 3224-8909

\section{RESUMO}

Tendo em vista as especificidades da contabilidade aplicada ao setor petrolífero, como a utilização de modelo próprio de reconhecimento e mensuração, além do fato de o principal ativo das empresas petrolíferas - suas reservas de petróleo e gás - não ser reconhecido atualmente em seus balanços, permanece viva a discussão acerca da relevância das informações contábeis produzidas por essas empresas. Nesse contexto, este estudo teve por objetivo geral avaliar a relevância do conjunto de informações reportado nas demonstrações contábeis das empresas

1 Artigo recebido em 14/10/2017. Revisado por pares em 03/01/2019. Reformulado em 15/02/2019. Recomendado para publicação em 06/03/2019 por Moacir M. Rodrigues Jr. Publicado em 30/03/2019. Organização responsável pelo periódico: FURB. 
petrolíferas para o mercado de capitais, por meio da técnica de estudo de eventos. Utilizou-se uma amostra composta por 752 observações relativas a 94 empresas petrolíferas atuantes no segmento de exploração e produção listadas na Bolsa de Valores de Nova Iorque - NYSE (New York Stock Exchange), referentes aos anos de 2006 a 2015. Os resultados demonstraram que as informações contábeis das empresas petrolíferas apresentam relevância. No entanto, esta relevância é viesada para baixo, tendo em vista que aumentou no biênio 2014/2015, período de baixa do preço do petróleo, e que predominaram movimentos de queda nos períodos próximos à divulgação, quando as observações de relevância sofrem acréscimo. Esses resultados reafirmam a relevância da contabilidade aplicada ao setor petrolífero.

Palavras-chave: Relevância da Informação Contábil; Estudo de Evento; Contabilidade Aplicada ao Setor de Petróleo e gás.

\section{ABSTRACT}

Given the specificities of accounting applied to the oil and gas sector, such as the use of its own recognition and measurement model, and the fact that the main asset of the oil companies - their oil and gas reserves - is not currently recognized in their balance sheets the discussion about the relevance of the accounting information produced by these companies remains alive. In this context, the main objective of this study was to evaluate the relevance of the information reported in the financial statements of the oil companies to the capital markets, using the technique of event study. We used a sample of 752 observations on 94 oil companies in the Exploration and Production segment listed on the New York Stock Exchange - NYSE (New York Stock Exchange) for the years 2006-2015. The results showed that the accounting information of the oil companies is relevant. However, this relevance is biased down, considering that it increased in the biennium 2014/2015, a period of low oil prices and that there were predominant movements of decline in the periods close to the disclosure when the observations of relevance increase. These results reaffirm the relevance of accounting applied to the petroleum sector.

Keywords: Value relevance of Accounting Information; Event Study; Oil and Gas Accounting.

\section{RESUMEN}

En vista de las especificidades de la contabilidad aplicada al sector petrolero, como la utilización de modelo propio de reconocimiento y medición, además de que el principal activo de las empresas petroleras - sus reservas de petróleo y gas- no es reconocido actualmente en sus balances, permanece viva la discusión sobre la relevancia de la información contable producida por dichas empresas. En este contexto, este estudio tuvo por objetivo general evaluar la relevancia del conjunto de informaciones reportado en las demostraciones contables de las empresas petroleiras para o mercado de capitales, por medio de la técnica de estudio de eventos. Se ha utilizado una muestra compuesta por 752 observaciones relativas a 94 empresas petroleras actuantes en el segmento de exploración y producción listadas en la Bolsa de Nueva YorkNYSE (New York Stock Exchange), referentes a los años de 2006 hasta 2015. Los resultados demostraron que las informaciones contables de las empresas petroleras presentan relevância. Sin embargo esta relevância es sesgada hacia abajo, teniendo en cuenta que aumentó en el bienio 2014/2015, período de baja del precio del petróleo, y que predominaron los movimientos de la baja en los períodos próximos a la divulgación, cuando las observaciones de relevancia sufren acrecimiento. Estos resultados reafirman la relevancia de la contabilidad aplicada al sector petrolero.

Palabras-clave: Relevancia de la Información Contable; Estudio de Eventos; Contabilidad Petrolera. 


\section{INTRODUÇÃO}

Sabe-se que o objetivo das demonstrações contábeis é fornecer informações úteis sobre as empresas a investidores existentes e em potencial, a credores por empréstimos e a outros credores, quando da tomada decisão ligada ao fornecimento de recursos à entidade. Tais decisões envolvem comprar, vender ou manter participações em instrumentos patrimoniais e em instrumentos de dívida e oferecer ou disponibilizar empréstimos ou outras formas de crédito (IASB, 2010).

Ainda segundo o International Accounting Standards Board (IASB), para ser considerada útil, a informação contábil-financeira precisa ser relevante, ou seja, ser capaz de fazer diferença nas decisões que possam ser tomadas pelos usuários. Nesse sentido, a satisfação do objetivo das demonstrações contábeis se alicerça na relevância das informações divulgadas aos usuários.

Segundo MACEDO et al (2011), com o intuito de averiguar a relevância de determinada informação contábil para o mercado de capitais, analisando se tais informações estão refletidas no preço das ações das empresas, são realizadas pesquisas, denominadas "value relevance", que analisam a relação entre os valores de mercado das empresas e os números fornecidos pela contabilidade. Baseadas no modelo de Ohlson (1995), a lógica das pesquisas desta natureza está em considerar que a associação dos números contábeis com os valores de mercado das ações das empresas contribui para definir se a informação é relevante ou não.

Em virtude de seu tamanho e importância, tanto energética quanto econômica, as informações relativas às empresas petrolíferas são acompanhadas por um grande número de investidores e analistas financeiros, cuja preocupação principal é tentar predizer com sucesso o comportamento do preço das ações dessas companhias (MISUND; OSMUNDSEN; ASCHE, 2005).

Neste contexto, tendo em vista a magnitude da indústria de petróleo e gás, e em virtude das especificidades da contabilidade aplicada ao setor, a verificação de sua eficácia como fornecedora de informações úteis a seus usuários, tem sido objeto de diversos estudos, dentre os quais Quirin, Berry e O’Bryan (2000), Misund, Osmundsen e Asche (2005), Santos e Silva (2015) e Domingues e Ribeiro (2016).

Dentre as especificidades mencionadas, destacam-se a utilização de modelo próprio de reconhecimento e mensuração e o fato de o principal ativo das empresas petrolíferas - suas reservas de petróleo e gás - não ser reconhecido atualmente em seus balanços. Embora o debate não seja recente, o tema continua não sendo pacífico, como exemplificam os trabalhos de Harris e Ohlson (1987), Santos e Silva (2015) e Domingues e Ribeiro (2016).

Tendo em vista a relevância econômica, financeira e energética da indústria petrolífera mundial e considerando as particularidades da contabilidade aplicada ao setor, o problema da presente pesquisa pode ser sintetizado no seguinte questionamento: Qual a reação do mercado de capitais à divulgação das informações contábeis das empresas petrolíferas?

Partindo da reflexão apresentada, o objetivo geral é avaliar, por meio do emprego da técnica de estudo de eventos, a relevância do conjunto de informações reportado nas demonstrações contábeis das empresas petrolíferas para o mercado de capitais. E, além disso, analisar o comportamento do mercado nos cenários antes e depois do evento "publicação das demonstrações contábeis". Desta forma, a hipótese deste estudo é, portanto: O conjunto de informações reportado nas demonstrações contábeis das empresas petrolíferas é relevante para o mercado de capitais.

Grandes investidores e investidores institucionais podem dispor de sistemas de avaliação sofisticados e de grande número de analistas dedicados a cobrir o setor de petróleo e gás no mercado de capitais, condição de que não dispõem pequenos e médios investidores. Desta forma, o estudo justifica-se por investigar se as informações reportadas nas demonstrações contábeis das empresas petrolíferas cumprem seu objetivo de fornecer 
informações úteis acerca da entidade a seus usuários ou se falha no cumprimento de seu papel de redutora da assimetria informacional existente no mercado.

Considerando que o tema da relevância das demonstrações contábeis das empresas petrolíferas não é pacífico, como demonstram os estudos de Harris e Ohlson (1987), Santos e Silva (2015) e Domingues e Ribeiro (2016), a reflexão acerca do cumprimento do objetivo destas demonstrações é pertinente e deve acontecer no âmbito dos órgãos normatizadores, mas sua aferição empírica está na seara da academia. Por este ponto de vista, a contribuição desta pesquisa pode ser de grande valia aos órgãos normatizadores, como, IASB, FASB e Comitê de Pronunciamentos Contábeis (CPC), para subsidiar tal reflexão a partir do fornecimento de uma análise baseada em dados concretos. Sob a perspectiva das empresas e dos preparadores de informações contábeis, faz sentido verificar se esta atividade é eficaz.

\section{REFERENCIAL TEÓRICO}

\subsection{Relevância da informação contábil para o mercado de capitais}

Para ser considerada útil, a informação contábil-financeira precisa ser relevante, isto é, ser capaz de fazer diferença nas decisões que possam ser tomadas pelos usuários. Nesse sentido, a satisfação do objetivo das demonstrações contábeis se alicerça na relevância das informações divulgadas aos usuários.

Sob este aspecto, o estudo do papel da contabilidade como fornecedora de informações para o mercado de capitais é de extrema importância para a avaliação da eficiência da informação contábil (IUDÍCIBUS; LOPES, 2008). Com o intuito de aferir, empiricamente, a relevância de determinada informação contábil para o mercado de capitais, são realizadas pesquisas cuja lógica, de acordo com Barth, Beaver e Landsman (2001), está em considerar que a associação dos números contábeis com os valores de mercado das ações das empresas contribui para definir se a informação contábil é relevante ou não.

De acordo com Fama (1991), a Hipótese dos Mercados Eficientes - Efficient Markets Hypotesis $(\mathrm{EMH})$ - define que os preços das ações refletem toda e qualquer informação relevante e disponível e ajustam-se aos riscos e retornos esperados em função desse conjunto de informações. Ainda segundo os autores, tendo como base a EMH, diversos estudos têm sido realizados com o objetivo de verificar a relevância das informações contábeis na formação do preço das ações no mercado. Pesquisas desta natureza estão inseridas, de acordo com Watts e Zimmerman (1990), no escopo da Teoria Positiva da Contabilidade.

Especificamente, esta teoria tem a preocupação de explicar e predizer as escolhas contábeis em termos das informações divulgadas (WATTS; ZIMMERMAN, 1990). Na abordagem da Teoria Positiva da Contabilidade, procuram-se estabelecer hipóteses de pesquisa, advindas, em geral, da teoria econômica e das finanças, e testá-las empiricamente, verificando o real comportamento dos agentes econômicos frente à informação contábil (LOPES; MARTINS, 2005). Fama (1970) aprimora o conceito da EMH, ressaltando que, na prática, os mercados não são totalmente eficientes e apresenta uma classificação para os mercados de acordo com o nível de incorporação das informações pelos preços dos ativos.

Assim, o mercado pode ser eficiente na forma fraca, quando apenas as informações passadas estariam incorporadas nos preços; na forma semiforte, onde somente as informações publicamente disponíveis (como por exemplo: divulgação de resultados anuais, desdobramento de ações) estariam refletidas nos preços; e por último, na forma forte, na qual todas as informações estariam incorporadas nos preços.

Holthausen e Watts (2001) ressaltam que a comparação de números contábeis com variáveis implícitas no preço das ações só faz sentido se for assumido algum nível de eficiência do mercado. Já Ball e Brown (1968) utilizaram informações anuais de empresas, entre 1946 e 1966, para analisar a reação dos preços de mercado às boas notícias (lucro acima das 
expectativas) e às más notícias (prejuízos inesperados), comprovando a existência de conteúdo informativo das demonstrações contábeis.

Beaver (1968) estudou informações anuais de empresas com ações negociadas na Bolsa de Nova Iorque, entre 1961 e 1965. Segundo o autor, os resultados contábeis são dotados de capacidade informacional, ou seja, existe uma relação positiva entre a informação contábil relevante e os preços das ações no mercado, já que esses refletem as expectativas dos agentes econômicos em relação ao comportamento da economia e do futuro da empresa.

Assim, desde os trabalhos destes pioneiros, desenvolvem-se pesquisas empíricas neste mesmo estilo, isto é, que analisam a relação entre o mercado de capitais e as demonstrações financeiras, linha de pesquisa que se convencionou chamar Capital Market-Based Accounting Research (CMBAR), existindo, segundo Kothari (2001), basicamente dois modelos nessa linha, quais sejam, estudos de evento e estudos de associação. Conforme Kothari (2001), no primeiro modelo, é verificado se um evento, como por exemplo a divulgação de demonstrações contábeis de uma empresa, traz informação nova aos agentes do mercado, refletindo-se em alterações significativas no nível ou na variância dos preços ou no volume de negociações de suas ações, em períodos curtos de tempo, ao redor do evento.

Já em estudos de associação, é verificado se existe correlação positiva entre uma variável contábil, como por exemplo lucro ou fluxo de caixa operacional, e o retorno das ações da respectiva empresa, ambos avaliados em um período relativamente longo, em períodos concomitantes, como um ano, por exemplo (KOTHARI, 2001). Barth, Beaver e Landsman (2001) ressaltam, inclusive, que embora estudos que discutem a relação entre números contábeis e mercado de capitais remontem ao final da década de 1960 e que os estudos de Ball e Brown (1968) e Beaver (1968) sejam geralmente referidos com estudos de value relevance, o conceito dessa metodologia foi efetivamente desenvolvido apenas na primeira metade da década de 1990, por Amir, Harris e Venuti (1993).

Amir, Harris e Venuti (1993) investigaram se ajustes de reconciliação no resultado e no patrimônio líquido, para o padrão contábil norte-americano de empresas estrangeiras, por meio da emissão do Form 20-F, aumentavam a associação entre as informações contábeis e o preço ou retorno das ações. O objetivo foi identificar a relevância de tais ajustes em uma amostra de empresas de 20 países diferentes, que possuíam ações listadas na Bolsa de Valores de Nova Iorque (NYSE). Os resultados evidenciaram que as reconciliações possuíram relevância incremental em relação às informações divulgadas no sistema contábil do país de origem das empresas.

De maneira geral, os estudos de value relevance empregam análise de regressão, que possui o preço das ações como variável dependente e as informações contábeis como variáveis independentes. $\mathrm{O}$ foco dos estudos desta natureza é verificar o quanto o comportamento das variáveis contábeis é capaz de explicar o comportamento dos preços das ações (MACEDO et al, 2011).

\subsection{Pesquisas de value relevance aplicadas ao setor de petróleo e gás}

Para compreender adequadamente o escopo, os achados e as implicações das pesquisas de value relevance aplicadas ao setor de petróleo e gás, torna-se indispensável contextualizar, ainda que resumidamente, as especificidades da contabilidade aplicada ao setor. De acordo com o padrão contábil norte-americano, as empresas petrolíferas possuem modelo próprio de reconhecimento e mensuração, podendo optar livremente entre dois métodos de contabilização de suas atividades de exploração e produção, quais sejam: esforços bem-sucedidos (successful efforts) e capitalização total (full cost).

No âmbito do normatizador internacional, como expõem Santos, Silva e Santos (2015), desde 1998, tenta-se, sem sucesso, emitir uma norma para o setor petrolífero, chegando ao International Financial Reporting Standard $\mathrm{n}^{\circ} 6$ - Exploration for and Evaluation of Mineral 
Asset (IFRS 6), emitido em 2004, que entrou em vigor em $1^{\circ}$ de janeiro de 2006 . No entanto, o IFRS 6 não tomou qualquer posição na discussão do método dos esforços bem-sucedidos versus custo total, ao contrário, permitiu a continuidade da escolha entre os métodos (CORTESE; IRVINE, 2010).

Essa particularidade de tratamento contábil, a discricionariedade na escolha do método e seus claros efeitos diversos sobre os relatórios financeiros suscitam a discussão acerca de seus potenciais efeitos sobre a relevância da informação produzida pela contabilidade destas empresas.

Outra especificidade da contabilidade aplicada ao setor petrolífero, de acordo com Santos e Silva (2014), diz respeito ao fato de o valor do principal ativo das empresas petrolíferas, suas reservas, não ser reconhecido atualmente em seus balanços. No máximo, ativam-se os gastos incorridos na aquisição, na exploração e na viabilização da extração (desenvolvimento) do petróleo e do gás.

Segundo Münch et al. (2007), destaca-se a importância das reservas para as empresas do setor de petróleo e gás e para todo o mercado, pois elas representam um "estoque oculto" de uma mercadoria com alto valor comercial, que afeta diretamente o lucro e longevidade de uma companhia.

Nesse contexto, as pesquisas de value relevance aplicadas ao setor de petróleo e gás, de modo geral, buscam averiguar a relevância das informações contábeis das empresas petrolíferas e compará-las às informações complementares, de disclosure obrigatório para empresas que publicam no mercado de capitais norte-americano, acerca das atividades de exploração e produção. Dentre estes dados complementares, constam, principalmente, os volumes de reservas provadas de petróleo e gás, além de informações sobre volumes de produção e de descoberta e fluxo de caixa futuro, considerando o volume atual de reservas (DOMINGUES; RIBEIRO, 2016).

Contextualizadas as especificidades da contabilidade aplicada ao setor de petróleo e gás, são apresentados no Quadro 1 os objetivos e os achados das pesquisas de value relevance aplicadas ao setor.

Quadro 1 - Pesquisas de value relevance no setor petrolífero

\begin{tabular}{|c|c|c|}
\hline Estudo & Objetivo & Resultado \\
\hline Teall (1992) & $\begin{array}{l}\text { Determinar qual dentre três } \\
\text { informações relativas às reservas de } \\
\text { petróleo e gás (custo histórico } \\
\text { capitalizado, volume ou fluxos de } \\
\text { caixa descontados) possui mais } \\
\text { conteúdo informacional incremental } \\
\text { em relação ao lucro. }\end{array}$ & $\begin{array}{l}\text { A divulgação conjunta das três informações } \\
\text { aumentou o conteúdo informacional dos } \\
\text { relatórios. Analisadas individualmente, nenhuma } \\
\text { delas se mostrou relevante. }\end{array}$ \\
\hline $\begin{array}{l}\text { Clinch e Magliolo } \\
\text { (1992) }\end{array}$ & $\begin{array}{l}\text { Investigar se a divulgação relativa aos } \\
\text { volumes de reservas e da produção, de } \\
\text { acordo com as exigências do SFAS 69, } \\
\text { possuíam conteúdo informacional. }\end{array}$ & $\begin{array}{l}\text { Apenas a produção apresentou relevância para o } \\
\text { mercado de capitais. }\end{array}$ \\
\hline Alciatore (1993) & $\begin{array}{l}\text { Averiguar a relevância das } \\
\text { informações relativas às reservas, } \\
\text { tendo por base dez itens divulgáveis } \\
\text { exigidos pelo SFAS } 69 .\end{array}$ & $\begin{array}{l}\text { As informações relativas às quantidades } \\
\text { produzidas, volume descoberto no período, } \\
\text { quantidades de reservas vendidas, mudanças } \\
\text { decorrentes das estimativas do período anterior, } \\
\text { mudanças nos preços do barril de petróleo } \\
\text { utilizado nas estimativas e mudanças na alíquota } \\
\text { do imposto sobre lucro possuem poder } \\
\text { informacional incremental quando comparados a } \\
\text { outros itens exigidos pelo SFAS } 69 \text { e ao lucro } \\
\text { líquido. }\end{array}$ \\
\hline
\end{tabular}



COMPANHIAS BRASILEIRAS

\begin{tabular}{|c|c|c|}
\hline Spear (1994) & $\begin{array}{l}\text { Aferir a relação entre o retorno não } \\
\text { esperado das ações e os componentes } \\
\text { da variação anual no volume das } \\
\text { reservas de petróleo. }\end{array}$ & $\begin{array}{l}\text { As descobertas de novas reservas e as revisões } \\
\text { das estimativas do período anterior possuem } \\
\text { poder informativo incremental, entretanto, não se } \\
\text { pode afirmar o mesmo em relação às variações } \\
\text { líquidas no valor padronizado das reservas. }\end{array}$ \\
\hline $\begin{array}{l}\text { Johnsen, Paxson } \\
\text { e Rizzuto (1996) }\end{array}$ & $\begin{array}{l}\text { Testaram a associação entre o valor de } \\
\text { mercado de empresas de petróleo e gás } \\
\text { e variáveis contábeis e econômicas. }\end{array}$ & $\begin{array}{l}\text { As evidências sugerem que o foco dos } \\
\text { investidores não estaria voltado aos valores } \\
\text { contábeis, mas sim aos valores econômicos das } \\
\text { empresas. }\end{array}$ \\
\hline $\begin{array}{l}\text { Quirin, Berry e } \\
\text { O’Bryan (2000) }\end{array}$ & $\begin{array}{l}\text { Verificar o conteúdo informacional do } \\
\text { patrimônio líquido, do lucro por ação e } \\
\text { de nove outras variáveis, escolhidas } \\
\text { por meio de pesquisa junto analistas } \\
\text { financeiros especializados no setor. }\end{array}$ & $\begin{array}{l}\text { As variáveis analisadas fornecem informações } \\
\text { incrementais relevantes. }\end{array}$ \\
\hline Boone (2002) & $\begin{array}{l}\text { Investigar a fraca relevância, } \\
\text { apresentada em pesquisas anteriores, } \\
\text { com relação à avaliação a valor } \\
\text { presente dos ativos de óleo e gás. }\end{array}$ & $\begin{array}{l}\text { Ativos de petróleo e gás mensurados a valor } \\
\text { presente explicam melhor a variação nos preços } \\
\text { das ações do que os ativos medidos pelo custo } \\
\text { histórico. }\end{array}$ \\
\hline $\begin{array}{l}\text { Misund, } \\
\text { Osmundsen e } \\
\text { Asche (2005) }\end{array}$ & $\begin{array}{l}\text { Determinar o value relevance relativo } \\
\text { aos números contábeis das } 15 \text { maiores } \\
\text { empresas internacionais de petróleo e } \\
\text { gás. }\end{array}$ & $\begin{array}{l}\text { Os números contábeis, calculados antes da } \\
\text { contabilização da depreciação são mais } \\
\text { relevantes do que os valores líquidos. Isso indica } \\
\text { que os investidores têm mais confiança nos } \\
\text { lucros antes da depreciação e nos fluxos de caixa } \\
\text { que no lucro líquido. } \\
\text { O tamanho das reservas de petróleo é importante } \\
\text { para explicar o valor das maiores empresas } \\
\text { internacionais de petróleo e gás. }\end{array}$ \\
\hline $\begin{array}{l}\text { Osmundsen et al } \\
(2006)\end{array}$ & $\begin{array}{l}\text { Analisar empresas petrolíferas } \\
\text { internacionais procurando estabelecer } \\
\text { relações econométricas entre o valor } \\
\text { de mercado das empresas e seus } \\
\text { indicadores financeiros e operacionais. }\end{array}$ & $\begin{array}{l}\text { Os resultados não sugerem relação significativa } \\
\text { entre o Return on Average Capital Employed } \\
\text { (RoACE) e múltiplos baseados no mercado. Por } \\
\text { outro lado, segundo a pesquisa, evidências } \\
\text { sugerem que o mercado acionário estaria cada } \\
\text { vez mais preocupado com a reposição de reservas } \\
\text { e com o crescimento sustentável da rentabilidade. }\end{array}$ \\
\hline $\begin{array}{l}\text { Ribeiro, Menezes } \\
\text { e Bone (2011) }\end{array}$ & $\begin{array}{l}\text { Avaliar o efeito da acumulação de } \\
\text { reservas de petróleo e gás sobre o valor } \\
\text { de mercado de empresas integradas do } \\
\text { setor. }\end{array}$ & $\begin{array}{l}\text { Os resultados demostraram que as reservas se } \\
\text { correlacionam positivamente com o preço de } \\
\text { mercado das empresas. Todavia, o mercado } \\
\text { parece penalizar uma estratégia de aumento de } \\
\text { reservas sem contrapartida de aumento de lucros } \\
\text { ou Patrimônio Líquido (PL). }\end{array}$ \\
\hline $\begin{array}{l}\text { Santos e Silva } \\
(2015)\end{array}$ & $\begin{array}{l}\text { Analisar variáveis contábeis e não } \\
\text { contábeis de empresas petrolíferas. } \\
\text { As variáveis não contábeis analisadas } \\
\text { foram: custo da descoberta por barril, } \\
\text { taxa de sucesso exploratório, } \\
\text { quantidade de reservas provadas e sua } \\
\text { variação e fluxo de caixa descontado } \\
\text { padronizado das reservas. }\end{array}$ & $\begin{array}{l}\text { Além do lucro líquido e do patrimônio líquido, } \\
\text { algumas informações específicas do setor } \\
\text { petrolífero mensuradas a valores históricos são } \\
\text { úteis aos usuários da informação em suas } \\
\text { decisões econômicas. }\end{array}$ \\
\hline $\begin{array}{l}\text { Domingues e } \\
\text { Ribeiro (2016) }\end{array}$ & $\begin{array}{l}\text { Investigar a relevância das } \\
\text { informações relacionadas às reservas } \\
\text { provadas de petróleo e das } \\
\text { informações contábeis (lucro e } \\
\text { patrimônio líquido) na avaliação de } \\
\text { petrolíferas mundiais. }\end{array}$ & $\begin{array}{l}\text { O valor de mercado de uma petrolífera é função } \\
\text { da variável contábil Patrimônio Líquido e de } \\
\text { informações relacionadas às reservas provadas de } \\
\text { petróleo e de gás, reforçando a ideia de que os } \\
\text { dados contábeis são informações incompletas } \\
\text { para a determinação do valor destas empresas. }\end{array}$ \\
\hline
\end{tabular}

Fonte: Elaboração própria.

Diante do exposto, é possível verificar que os trabalhos de Quirin, Berry e O’Bryan (2000), Misund, Osmundsen e Asche (2005), Santos e Silva (2015) e Domingues e Ribeiro (2016), testando variáveis distintas, concluem igualmente que as informações contábeis das 
empresas petrolíferas são relevantes para o mercado de capitais. A variável contábil mais utilizada nestes estudos para embasar esta conclusão foi o patrimônio líquido.

Por sua vez, os estudos de Teall (1992), Alciatore (1993), Spear (1994), Osmundsen et al (2006), Ribeiro, Menezes e Bone (2011) e também os mesmos Quirin, Berry e O’Bryan (2000), Misund, Osmundsen e Asche (2005), Santos e Silva (2015) e Domingues e Ribeiro (2016), utilizando diversas variáveis não contábeis, concluíram que as demonstrações contábeis das empresas de petróleo e gás, em termos de relevância, são incompletas, precisando ser complementadas por informações adicionais específicas do setor, tais como as exigidas pelo Accounting Standard Codification (ASC) 932 (antigo SFAS 69). Ressalte-se que todas estas pesquisas trabalharam com informações relativas às reservas de petróleo e gás.

Destaque-se que nos modelos analisados por Quirin, Berry e O’Bryan (2000), Misund, Osmundsen e Asche (2005), Ribeiro, Menezes e Bone (2011), Santos e Silva (2015) e Domingues e Ribeiro (2016), o conjunto de variáveis explicativas apresenta elevado poder explanatório do preço das ações das empresas petrolíferas.

Já as pesquisas de Clinch e Magliolo (1992), Johnsen, Paxson e Rizzuto (1996) e Boone (2002) apontam que o conjunto formado pelas demonstrações contábeis das empresas do setor e pelas exigências do SFAS 69 não apresentam conteúdo informacional.

Destarte, os achados desta pesquisa serão confrontados com os resultados dos estudos anteriores quanto a verificação e a análise da relevância das demonstrações contábeis das empresas petrolíferas.

\section{METODOLOGIA}

\subsection{Plano amostral}

Quanto à caracterização da população e da amostra, a seleção foi realizada de forma não probabilística e intencional, entretanto, seguindo algumas premissas que são apresentadas e justificadas a seguir.

A população foi composta pelas empresas que atuam nas fases de exploração e produção de petróleo e gás natural com ações negociadas na Bolsa de Valores de Nova Iorque - NYSE (New York Stock Exchange) na data base de agosto de 2016, analisando-se o período de 2006 a 2015. A NYSE foi selecionada por representar um dos maiores e mais sólidos mercados de capitais do mundo, o mercado norte-americano, onde empresas de diversos países buscam recursos e, portanto, onde têm seus títulos negociados.

A lista de empresas foi extraída por meio de consulta ao site da NYSE, obedecendo à taxonomia de classificação de setores utilizadas por essa bolsa de valores, o Industry Classification Benchmark (ICB). O ICB distingue 10 grupos industriais, subdividindo-os, sucessivamente, em supersetor, setor e subsetor. Dessa forma, foram considerados os seguintes parâmetros:

- indústria: petróleo e gás;

- supersetor: petróleo e gás;

- setor: produção de petróleo e gás.

Estabelecidos estes parâmetros, a população alvo contou com 95 empresas, correspondentes a todas as petrolíferas que atuam na área de exploração e produção de petróleo e gás natural com ações negociadas na Bolsa de Valores de Nova Iorque. Das 950 observações em potencial, para 157 não foi possível determinar a data de divulgação das demonstrações financeiras. Adicionalmente, para 41 observações, não foi possível estabelecer cotações suficientes para a construção das janelas de estimação e de evento. Em virtude desta indisponibilidade de dados, uma empresa foi completamente excluída. Desta forma, a amostra final foi composta por 752 eventos relativos a 94 empresas. 
As 94 empresas que compõem a amostra final apresentam as seguintes características: 65 empresas são norte-americanas, sendo que 38 seguem o padrão contábil dos esforços bemsucedidos e 27 a capitalização total; 29 empresas são estrangeiras com ações negociadas na NYSE e seguem as IFRS, sendo que 23 adotam o método dos esforços bem-sucedidos e 6 a capitalização total. Do total, 20 empresas são classificadas como integradas. O valor de mercado destas empresas em 31/12/2015 somava aproximadamente US\$ 1,7 trilhão. A relação completa das empresas encontram-se no Anexo A.

As datas das divulgações necessárias foram consultadas no site da US Securities and Exchange Commission - SEC, órgão regulador do mercado de capitais norte-americano, onde as empresas com ações negociadas na Bolsa de Nova Iorque são obrigadas a arquivar suas demonstrações.

No site Yahoo Finance foram levantadas as cotações diárias históricas das ações em escopo, devidamente ajustadas pelo pagamento de dividendos e pelo desdobramento de ações. Adicionalmente, foram resgatadas do site da NYSE, as cotações históricas do NYSE ARCA OIL $\operatorname{INDEX}(X O I)$, índice utilizado como parâmetro de comportamento normal das ações do setor. Ele é um benchmark da própria bolsa, projetado para medir a performance da indústria de petróleo e gás, por meio da variação dos preços de ações do setor, negociadas nessa bolsa de valores, estabelecido desde 1984, sendo formado pela ponderação dos preços dessas ações, tendo sua composição revista trimestralmente.

\subsection{Modelo de estudo}

Considerando a hipótese desta pesquisa de que o conjunto de informações reportado nas demonstrações contábeis das empresas petrolíferas é relevante para o mercado de capitais, foi utilizada a técnica de estudo de evento para operacionaliza-la.

Segundo Campbell, Lo e MacKinlay (1997), esta metodologia consiste em na análise do efeito da divulgação de informações específicas de determinada entidade sobre o preço de suas ações. O estudo de evento abrange as seguintes etapas: (1) Definição do Evento; (2) Critério de Seleção; (3) Retornos Normais e Anormais; (4) Procedimento de Estimação; (5) Procedimento de Teste e (6) Resultados Empíricos.

Neste sentido, a definição do evento considerada foi a data da divulgação das demonstrações contábeis anuais das empresas componentes da amostra, relativas aos 10 exercícios em escopo, ou seja, de 2006 a 2015.

Estabelecida a data do evento (data zero) foram definidas as janelas de estimação, e de evento. Buscando minimizar o efeito da subjetividade da escolha da duração da janela de evento e proporcionar comparabilidade, para cada observação, foram construídas três janelas de eventos, que contaram com 1, 5 e 10 dias antes e após o evento, além do próprio dia da divulgação das demonstrações contábeis. Desta forma, as janelas de eventos contaram com 3, 11 e 21 dias.

O período utilizado para estimar o retorno normal denomina-se janela de estimação, que segundo Campbell, Lo e Mackinlay (1997), deve ser de, no mínimo, 120 dias. Por essa razão, as respectivas janelas de estimação, foram compostas pelos 120 pregões imediatamente anteriores às janelas de eventos, gerando, portanto, três janelas de estimação distintas para cada observação.

Selecionadas as cotações, realizou-se o cálculo dos retornos diários das ações, utilizando-se a fórmula logarítmica, $(1) \mathrm{r}=\ln \left(P_{t} / P_{t-1}\right)$ em virtude de suas vantagens quando comparada a fórmula discreta.

No procedimento de testes, foi utilizado o Modelo de Retornos Ajustados ao Risco e ao Mercado (Modelo de Mercado) para calcular os retornos anormais, considerando que, segundo Costa Junior (2008), este é o modelo mais sensível à percepção de reações do mercado, sendo amplamente difundido nas pesquisas que utilizam estudo de eventos, como defendido por 
Brown e Warner (1980). O Modelo de Mercado caracteriza-se por ser um dos modelos estatísticos que têm uma relação linear entre o retorno do portfólio de mercado, neste caso o NYSE ARCA OIL INDEX (XOI), com o retorno de um determinado ativo, no caso, o retorno das ações analisadas, através da utilização de regressão linear.

Na composição dos retornos, para preencher as janelas de estimação e evento, nos casos de períodos sem cotação, foi utilizado o procedimento Trade-to-Trade para solucionar este problema, no intuito de não enviesar a análise.

Calculados os retornos, aplicou-se a fórmula para encontrar os retornos anormais. Essa fórmula consiste na subtração do retorno esperado do retorno observado, para se chegar ao retorno anormal. Obtido o retorno observado, foi aplicada a fórmula (2) $R_{i t}=\alpha_{i}+\beta \mathrm{Rmt}+$ $\varepsilon_{i t}=\mathrm{E}\left(R_{i t} \mid X_{i t}\right)+\varepsilon_{i t}$, onde a variável dependente foi o retorno observado e a variável independente foi o retorno do NYSE ARCA OIL INDEX (XOI) (TAKAMATSU, LAMOUNIER e COLAUTO, 2008).

O cálculo do retorno anormal á dado por:

$$
A R_{i t}=R_{i t}-\alpha_{i}-\beta R_{m t}
$$

onde:

$A R_{i t}$ é o retorno anormal;

$R_{i t}$ é o retorno observado;

$\left(\alpha_{i}+\beta R_{m t}\right)$ é o retorno esperado.

Com a finalidade de avaliar a relevância das demonstrações contábeis do setor como um todo, promoveu-se a acumulação dos retornos anormais, em cada uma das três janelas de evento, para toda a série de 752 observações empresas/ano. Como procedimento análogo, avaliou-se também as séries de retornos anormais acumulados para cada um dos 10 anos em escopo, 2006 a 2015.

Aplicou-se o teste Kolmogorov-Smirnov (K-S) para verificar se as séries de retornos anormais acumulados possuíam distribuição normal, o que determinaria a escolha entre o teste paramétrico $\mathrm{T}$ e o do teste não paramétrico dos Sinais. Considerando o nível de significância de 5\%, utilizou-se o teste paramétrico $\mathrm{T}$ como instrumento de verificação da igualdade ou da desigualdade dos retornos anormais acumulados. Para os casos do teste não paramétrico, foi verificado, estatisticamente, se o número de diferenças com sinal negativo é aproximadamente igual ao número de diferenças com sinal positivo.

Com objetivo de traçar um perfil qualitativo da relevância investigada, complementarmente, como metodologia alternativa, cada um dos 752 casos foi analisado individualmente, comparando-se as séries de retornos anormais na janela de estimação com a série se retornos anormais das janelas de eventos. Para este fim, foi efetuado o teste não paramétrico U de Mann-Whitney para os retornos anormais nas janelas de estimação e de evento, para verificar se seriam estatisticamente diferentes. Optou-se pelo teste não paramétrico por não haver sentido em testar a normalidade em amostra tão reduzida quanto na janela de evento.

Neste sentido, constatada perturbação relevante nos preços das ações, quando da divulgação das respectivas demonstrações, seria possível afirmar que o conjunto de informações divulgado por esta empresa no ano em escopo foi relevante para o mercado de capitais. Posteriormente, foram calculados percentuais relativos aos casos estatisticamente significativos frente aos casos totais analisados, isto é, 752.

Identificados casos de perturbação significativa, foram analisadas as médias das variações das cotações na janela de evento para identificar se prevaleceriam movimentos de 
alta ou de baixa das respectivas ações. Adicionalmente, as janelas de eventos foram subdivididas em dois grupos, quais sejam: antes e depois do evento. O grupo "Antes" é composto exclusivamente pelos 10, 5 e 1 dia(s) anteriores à divulgação. Já o grupo "Depois" compreende o próprio dia do evento mais os 10, 5 e 1 dia(s) subsequentes.

Para todos os testes estatísticos, foi utilizado o Statistical Package for the Social Sciences - SPSS, versão 22.

\section{APRESENTAÇÃO E ANÁLISE DOS RESULTADOS}

São apresentados na Tabela 1, os resultados do teste Kolmogorov-Smirnov (K-S) para a série completa de 752 observações, com retornos anormais acumulados, para cada uma das três janelas de eventos. Como pode ser observado, a hipótese de normalidade da série foi rejeitada.

Tabela 1 - Teste para distribuição normal da série completa

\begin{tabular}{lccc}
\hline Teste K-S & $\mathbf{1}$ dia & $\mathbf{5}$ dias & $\mathbf{1 0}$ dias \\
\hline Estatística Z & 0,137 & 0,141 & 0,126 \\
P-valor & 0,000 & 0,000 & 0,000 \\
\hline Resultado & Sinais & Sinais & Sinais \\
\hline
\end{tabular}

Fonte: Resultados da pesquisa.

O mesmo resultado foi encontrado para maior parte das séries anuais, onde foram analisados individualmente os 10 anos em escopo, com exceção apenas para os 6 casos listados na Tabela 2, para os quais as séries de retornos anormais acumulados apresentaram distribuição normal.

Tabela 2 - Teste para distribuição normal das séries anuais

\begin{tabular}{lcccccc}
\hline \multirow{2}{*}{ Teste K-S } & \multicolumn{2}{c}{$\mathbf{2 0 0 7}$} & $\mathbf{2 0 0 9}$ & \multicolumn{2}{c}{$\mathbf{2 0 1 0}$} & $\mathbf{2 0 1 1}$ \\
\cline { 2 - 7 } & $\mathbf{1 ~ d i a}$ & $\mathbf{5}$ dias & $\mathbf{1 ~ d i a}$ & $\mathbf{5}$ dias & $\mathbf{1 0}$ dias & $\mathbf{5}$ dias \\
\hline Estatística Z & 0,092 & 0,076 & 0,079 & 0,099 & 0,076 & 0,102 \\
P-valor &, $200^{*}$ &, $200^{*}$ &, $200^{*}$ & 0,080 &, $200^{*}$ & 0,057 \\
\hline Resultado & Teste T & Teste T & Teste T & Teste T & Teste T & Teste T \\
\hline
\end{tabular}

Fonte: Resultados da pesquisa.

Com base no resultado dos testes de normalidade, realizaram-se os testes não paramétricos dos Sinais para a série completa, conforme demonstrado na Tabela 3.

Tabela 3 - Resultado dos testes de significância

\begin{tabular}{l|c|c|c}
\hline & $\mathbf{1}$ dia & $\mathbf{5}$ dias & $\mathbf{1 0}$ dias \\
\hline RAA & $-0,035$ & 6,241 & 13,538 \\
Estatística & $-23,733$ & $-23,706$ & $-23,408$ \\
\hline P-valor & 0,000 & 0,000 & 0,000 \\
\hline
\end{tabular}

Fonte: Resultados da pesquisa.

Os resultados indicam a aceitação da hipótese deste estudo, ou seja, verificou-se que o número de diferenças com sinal negativo foi estatisticamente diferente do número de diferenças com sinal positivo. Isto significa que o conjunto de informações reportado nas demonstrações contábeis das empresas petrolíferas é relevante para o mercado de capitais, tendo em vista os resultados estatisticamente significativos dos testes efetuados. A Tabela 3 apresenta ainda os retornos anormais acumuladas das séries e sua respectiva estatística. 
Com relação à avaliação das séries de retornos anormais acumulados para cada um dos 10 anos em escopo, 2006 a 2015, constatou-se o mesmo resultado para todos os anos e para todas as três janelas de eventos, indicando que para todos os anos analisados o conjunto de informações reportado nas demonstrações contábeis das empresas petrolíferas foi relevante, diante dos resultados estatisticamente significativos unânimes para os testes efetuados.

Com relação aos procedimentos metodológicos adicionais, visando analisar características adicionais do indicativo de relevância das demonstrações contábeis das empresas petrolíferas, cada um dos 752 casos foi analisado individualmente, comparando-se as séries de retornos anormais na janela de estimação com a série se retornos anormais das janelas de eventos. Posteriormente, foram calculados percentuais relativos aos casos estatisticamente significativos, isto é, para os quais houve detecção de comportamento distinto estatisticamente significativo na janela de evento em comparação à janela de estimação, frente aos casos totais analisados, conforme apresentado na Tabela 4.

Tabela 4 - Observações empresa/ano analisadas individualmente

\begin{tabular}{ccccccc}
\hline N. Confiança & $\mathbf{1}$ dia & $\mathbf{5}$ dias & $\mathbf{1 0}$ dias & $\mathbf{1 ~ d i a}$ & $\mathbf{5}$ dias & $\mathbf{1 0}$ dias \\
\hline $\mathbf{9 0 \%}$ & 123 & 77 & 84 & $16,36 \%$ & $10,24 \%$ & $11,17 \%$ \\
$\mathbf{9 5 \%}$ & 81 & 41 & 34 & $10,77 \%$ & $5,45 \%$ & $4,52 \%$ \\
$\mathbf{9 9 \%}$ & 25 & 14 & 6 & $3,32 \%$ & $1,86 \%$ & $0,80 \%$ \\
\hline \multicolumn{7}{r}{} \\
\hline
\end{tabular}

Fonte: Resultados da pesquisa.

Com base no exposto, de modo geral, quanto mais próxima a data de divulgação das demonstrações, maior foi a perturbação do mercado, ou seja, maior a relevância do evento analisado para as decisões de curto prazo dos agentes.

Dentre os casos de perturbação significativa identificados na Tabela 4, foram analisadas as médias das variações das cotações na janela de evento para identificar se prevaleceriam movimentos de alta ou de baixa das respectivas ações. Desta forma, os percentuais de altas dentre os casos de relevância são apresentados na Tabela 5.

Tabela 5 - Percentual de altas dentre os casos de relevância

\begin{tabular}{cccc}
\hline N. Confiança & $\mathbf{1}$ dia & $\mathbf{5}$ dias & $\mathbf{1 0}$ dias \\
\hline $\mathbf{9 0 \%}$ & $49,59 \%$ & $53,25 \%$ & $60,71 \%$ \\
$\mathbf{9 5 \%}$ & $53,09 \%$ & $63,41 \%$ & $67,65 \%$ \\
$\mathbf{9 9 \%}$ & $48,00 \%$ & $64,29 \%$ & $100,00 \%$ \\
\hline
\end{tabular}

Fonte: Resultados da pesquisa.

Nas janelas de 10 e 5 dias, prevaleceram movimentos de alta. No entanto, as proporções de altas vão reduzindo gradualmente do maior ao menor número de dias ao redor da divulgação, chegando a 49,59\% e $48 \%$ na janela de 1 dia antes e depois, ao nível de confiança de $90 \%$ e $99 \%$, respectivamente.

A Tabela 6 decompõe as observações apresentadas na Tabela 1 ao longo dos 10 anos analisados.

Tabela 6 - Casos de relevância ao longo dos anos

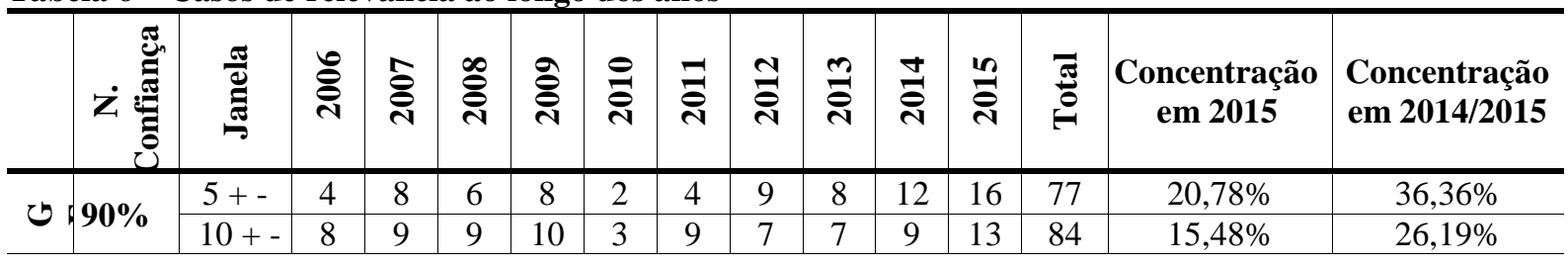


O IMPACTO DA OCPC 07 SOBRE O TAMANHO E A LEGIBILIDADE DAS NOTAS EXPLICATIVAS DE COMPANHIAS BRASILEIRAS

\begin{tabular}{c|c|c|c|c|c|c|c|c|c|c|c|c|c|c|c}
\hline & $1+-$ & 7 & 10 & 8 & 10 & 15 & 9 & 15 & 9 & 17 & 23 & 123 & $18,70 \%$ & $32,52 \%$ \\
\hline \multirow{4}{*}{$95 \%$} & $5+-$ & 1 & 6 & 1 & 5 & 1 & 2 & 5 & 2 & 8 & 10 & 41 & $24,39 \%$ & $43,90 \%$ \\
\cline { 2 - 15 } & $10+-$ & 3 & 4 & 2 & 2 & 0 & 2 & 5 & 6 & 4 & 6 & 34 & $17,65 \%$ & $29,41 \%$ \\
\cline { 2 - 14 } & $1+-$ & 4 & 8 & 6 & 5 & 8 & 5 & 9 & 7 & 12 & 17 & 81 & $20,99 \%$ & $35,80 \%$ \\
\hline \multirow{3}{*}{$99 \%$} & $5+-$ & 1 & 1 & 0 & 1 & 1 & 0 & 2 & 2 & 3 & 3 & 14 & $21,43 \%$ & $42,86 \%$ \\
\cline { 2 - 13 } & $10+-$ & 0 & 1 & 0 & 0 & 0 & 0 & 1 & 2 & 0 & 2 & 6 & $33,33 \%$ & $33,33 \%$ \\
\cline { 2 - 11 } & $1+-$ & 0 & 3 & 1 & 1 & 3 & 2 & 1 & 0 & 3 & 11 & 25 & $44,00 \%$ & $56,00 \%$ \\
\hline
\end{tabular}

Fonte: Resultados da pesquisa.

Percebe-se uma alta concentração de observações no ano de 2015. Aos três níveis de confiança trabalhados, 2015 sempre foi o ano que apresentou maior número de ocorrências de relevância, isto é, nas quais houve detecção de comportamento distinto estatisticamente significativo na janela de evento em comparação à janela de estimação.

Neste sentido, note-se, ainda, a alta concentração de ocorrências no biênio 2014/2015. Esta constatação possivelmente guarda relação com a baixa do preço do petróleo no mercado internacional, observada também no biênio 2014/2015.

É possível que a flutuação possa influenciar o interesse dos agentes do mercado em conhecer e tomar decisões de curto prazo no intuito de comprar, vender ou manter posições em função das perdas por impairment, ocasionadas pela queda da commodity, reportadas nas demonstrações financeiras das companhias petrolíferas.

Diante dos resultados encontrados para os testes realizados, depreende-se que o conjunto de informações reportado nas demonstrações contábeis das empresas petrolíferas é relevante para o mercado de capitais. Portanto, é possível afirmar que o presente estudo corrobora os achados de Teall (1992), Alciatore (1993), Spear (1994), Quirin, Berry e O`Bryan (2000), Misund, Osmundsen e Asche (2005), Osmundsen et al (2006), Ribeiro, Menezes e Bone (2011), Santos e Silva (2015) e Domingues e Ribeiro (2016) quanto a relevância das demonstrações contábeis e demais informações específicas do setor para o mercado de capitais.

Por outro lado, os achados desta pesquisa contrariam os resultados de Clinch e Magliolo (1992), Johnsen, Paxson e Rizzuto (1996) e Boone (2002), que não observaram conteúdo informacional das demonstrações contábeis das empresas do setor de óleo e gás.

Adicionalmente, as evidências desta pesquisa vão ao encontro dos resultados de Quirin, Berry e O’Bryan (2000), Misund, Osmundsen e Asche (2005), Ribeiro, Menezes e Bone (2011), Santos e Silva (2015) e Domingues e Ribeiro (2016), onde os conjuntos completos de variáveis explicativas apresentam elevado poder explanatório do preço das ações das empresas petrolíferas, já que o resultado dos testes estatísticos com retornos anormais acumulados foram, de forma unânime, estatisticamente significativos, tanto na série completa como nas séries anuais.

Portanto, resumidamente, os resultados que buscam satisfazer aos objetivos estabelecidos nesta pesquisa demonstram que embora o conjunto de informações reportado nas demonstrações contábeis das empresas petrolíferas seja relevante para o mercado de capitais e que tal relevância aumente em função da proximidade da data de divulgação, ela é viesada para baixo, tendo em vista que aumentou no biênio 2014/2015, período de baixa da commodity.

Este viés de incremento de relevância das demonstrações contábeis em movimentos de baixa pode ser justificado pelo fato de os números contábeis das empresas petrolíferas, em virtude de suas especificidades, não capturarem fatores de aumentos de valor da companhia com a mesma facilidade que reportam movimentos relevantes de baixa, como por exemplo, via reconhecimento de impairment, como foi observado no biênio 2014/2015.

Visando um entendimento adicional sobre a relevância das informações contábeis das empresas do setor de óleo e gás, as janelas de eventos foram subdivididas em dois grupos, quais sejam: antes e depois do evento em escopo. 
Analisando-se a Tabela 7 é possível constatar que o mercado se antecipa à divulgação. Percebe-se, inclusive, que no horizonte analisado, quanto mais distante a data de divulgação, maior é a perturbação, ou seja, maior é a relevância deste evento para as decisões de curto prazo. Os três níveis de confiança confirmam essa lógica. Destaque-se o fato de não haver ocorrência de evento relevante na janela 1 dia antes, ao nível de confiança de $99 \%$.

Tabela 7 - Janela "Antes"

\begin{tabular}{ccccccc}
\hline N. Confiança & $\mathbf{1}$ dia & $\mathbf{5}$ dias & $\mathbf{1 0}$ dias & $\mathbf{1 ~ d i a}$ & $\mathbf{5}$ dias & $\mathbf{1 0}$ dias \\
\hline $\mathbf{9 0 \%}$ & 72 & 81 & 89 & $9,57 \%$ & $10,77 \%$ & $11,84 \%$ \\
$\mathbf{9 5 \%}$ & 34 & 42 & 51 & $4,52 \%$ & $5,59 \%$ & $6,78 \%$ \\
$\mathbf{9 9 \%}$ & 0 & 8 & 12 & $0,00 \%$ & $1,06 \%$ & $1,60 \%$ \\
\hline \multicolumn{7}{c}{ Total de eventos } \\
\hline
\end{tabular}

Fonte: Resultados da pesquisa.

A detecção de retornos anormais estatisticamente significativos anteriores à divulgação das demonstrações contábeis confirma o conceito de Fama (1970) com relação à Hipótese dos Mercados Eficientes, de que na prática, os mercados não são totalmente eficientes.

Segundo a classificação de Fama (1970), com base nessas evidências, o mercado norte americano apresenta traços de um mercado forte, no qual informações ainda não tornadas públicas estariam refletidas nos preços dos ativos.

Como evidencia a Tabela 8 , não há comportamento homogêneo ou tendência dos movimentos de alta ou baixa das ações no grupo "Antes".

Tabela 8 - Percentual de altas dentre os casos de relevância na janela "Antes"

\begin{tabular}{cccc}
\hline N. Confiança & $\mathbf{1}$ dia & $\mathbf{5}$ dias & $\mathbf{1 0}$ dias \\
\hline $\mathbf{9 0 \%}$ & $50,00 \%$ & $58,02 \%$ & $49,44 \%$ \\
$\mathbf{9 5 \%}$ & $55,88 \%$ & $59,52 \%$ & $47,06 \%$ \\
$\mathbf{9 9 \%}$ & - & $50,00 \%$ & $58,33 \%$ \\
\hline
\end{tabular}

Fonte: Resultados da pesquisa.

Analisando o grupo "Depois", a Tabela 9 demonstra que o mercado se ajusta rapidamente à nova informação tornada pública, isto é, quanto mais próximo da data de divulgação, maior a perturbação, é dizer, o impacto do evento em questão nas decisões de curto prazo. Os três níveis de confiança corroboram este raciocínio.

Tabela 9 - Janela "Depois"

\begin{tabular}{ccccccc}
\hline N. Confiança & $\mathbf{1}$ dia & $\mathbf{5}$ dias & $\mathbf{1 0}$ dias & $\mathbf{1 ~ d i a}$ & $\mathbf{5}$ dias & $\mathbf{1 0}$ dias \\
\hline $\mathbf{9 0 \%}$ & 168 & 113 & 97 & $22,34 \%$ & $15,03 \%$ & $12,90 \%$ \\
$\mathbf{9 5 \%}$ & 120 & 59 & 47 & $15,96 \%$ & $7,85 \%$ & $6,25 \%$ \\
$\mathbf{9 9 \%}$ & 53 & 18 & 13 & $7,05 \%$ & $2,39 \%$ & $1,73 \%$ \\
\hline \multicolumn{7}{c}{ Total de eventos } \\
\hline
\end{tabular}

Fonte: Resultados da pesquisa.

Desta forma, na janela 1 dia "Depois", constatou-se a ocorrência de 22,34\%, 15,96\% e 7,05\% de casos de relevância, aos níveis de confiança de 90\%, 95\% e 99\%, respectivamente.

De acordo com a classificação de Fama (1970), com base nestas evidências, revelam-se resquícios de um mercado semiforte, onde somente as informações publicamente disponíveis estariam refletidas nos preços das ações.

A partir da Tabela 10, depreende-se, inclusive, que nesta maior perturbação capturada na janela 1 dia "Depois" predominam os movimentos de baixa das ações dentre os casos de 
O IMPACTO DA OCPC 07 SOBRE O TAMANHO E A LEGIBILIDADE DAS NOTAS EXPLICATIVAS DE COMPANHIAS BRASILEIRAS

variação significativa, chegando a 50,6\%, 51,67\% e 60,38\%, ao nível de confiança de $90 \%$, $95 \%$ e $99 \%$, respectivamente.

Tabela 10 - Percentual de altas dentre os casos de relevância na janela "Depois"

\begin{tabular}{cccc}
\hline $\mathbf{N}$. Confiança & $\mathbf{1}$ dia & $\mathbf{5}$ dias & $\mathbf{1 0}$ dias \\
\hline $\mathbf{9 0 \%}$ & $49,40 \%$ & $52,21 \%$ & $52,58 \%$ \\
$\mathbf{9 5 \%}$ & $48,33 \%$ & $49,15 \%$ & $57,45 \%$ \\
$\mathbf{9 9 \%}$ & $39,62 \%$ & $50,00 \%$ & $38,46 \%$ \\
\hline
\end{tabular}

Fonte: Resultados da pesquisa.

Este movimento corrobora o raciocínio de que a relevância das demonstrações contábeis das empresas petrolíferas é viesada para baixo, uma vez que o aumento de casos de retornos anormais vem acompanhado do aumento da proporção de movimentos de baixa dentre os casos estatisticamente significativos identificados.

\section{CONCLUSÃO}

Este estudo teve por objetivo avaliar, por meio do emprego da técnica de estudo de eventos, a relevância do conjunto de informações reportado nas demonstrações contábeis das empresas petrolíferas para o mercado de capitais. E, além disso, analisar o comportamento do mercado nos cenários antes e depois do evento "publicação das demonstrações contábeis".

Os resultados evidenciaram que o conjunto de informações divulgadas pelas empresas do setor de óleo e gás mostrou-se relevante para o mercado de capitais.

Desta forma, ainda que existam especificidades da contabilidade aplicada ao setor petrolífero, com base nos resultados apresentados neste estudo, o conjunto de informações composto pelas demonstrações contábeis propriamente ditas e pelas informações complementares, de disclosure obrigatório para empresas que publicam no mercado de capitais norte-americano, acerca das atividades de exploração e produção é relevante para o mercado.

Tais resultados estão em linha com os achados de grande parte dos estudos referenciados.

Outro achado diz respeito a constatação de que os agentes se antecipam à divulgação e que o mercado se ajusta rapidamente à nova informação tornada pública. Além disso, que predominam os movimentos de baixa das ações na janela 1 dia "Depois", representando que a relevância das demonstrações contábeis das empresas petrolíferas é viesada para baixo.

Um diferencial do presente estudo foi o emprego do indicador específico do setor - o NYSE ARCA OIL INDEX (XOI) para estabelecer o parâmetro de retornos normais e a amostra analisada, constituída por todas as empresas do setor de petróleo e gás que atuam no segmento de exploração e produção cujos papéis são negociados no mercado norte-americano, cobrindo um período de análise de 10 anos, de 2006 a 2015.

A investigação desta pesquisa justificou-se por reafirmar que a contabilidade aplicada ao setor petrolífero desempenha seu papel como linguagem do mundo dos negócios, reduzindo assim a assimetria de informação existente entre os participantes do mercado.

Destaque-se que esta pesquisa apresenta as limitações descritas por Richardson (2012) para os estudos quantitativos, tais como a adoção de procedimento predominantemente quantitativo para a explicação de fenômenos psicológicos e sociais complexos, a impossibilidade de transferência dos resultados para outras situações sociais e a impossibilidade de generalização das conclusões além do período em que o experimento ocorreu.

A pesquisa também ficou limitada à disponibilidade e à qualidade dos dados relativos às informações constantes nas bases de dados consultadas e à subjetividade da escolha das janelas de estimação e de evento. Tendo em vista que a data de divulgação das demonstrações 
contábeis varia entre empresas, a influência desta variação é intrínseca ao desenvolvimento deste estudo.

\section{REFERÊNCIAS}

ALCIATORE, M. L. New evidence on SFAS n ${ }^{\circ} .69$ and the components of the change in reserve value. The Accounting Review, v. 68, p. 639-656, 1993.

AMIR, E. HARRIS, T. S.; VENUTI, E. K. A comparison of the value-relevance of U.S. versus non-U.S. GAAP accounting measures using Form 20-F reconciliations. Journal of Accounting Research, v. 31, supplement, p. 230-264, 1993.

BALL, R.; BROWN, P. An empirical evaluation of accounting income numbers. Journal of Accounting Research. Chicago, p. 159-177, 1968.

BARTH, M. E.; BEAVER, W. H.; LANDSMAN, W. R. The relevance of value relevance literature for financial accounting standard setting: another view. Journal of Accounting and Economics, v. 31, p. 77-104, 2001.

BEAVER, W. H. The information content of annual earnings announcements. Journal of Accounting Research, v. 6, p. 67-92, 1968.

BOONE, J. P. Revisiting the reportedly weak value relevance of oil and gas asset present value: the roles of measurement error, model misspecification, and time-period idiosyncrasy. The Accounting Review, v. 77, n. 1, p. 73-106, 2002.

BROWN, S. J.; WARNER, J. B. Measuring security price performance. Journal of Financial Economics, Amsterdam: North Holland, v. 8, n. 3, p. 205-258, Set. 1980.

CAMPBELL, J. Y.; LO, A. W.; MACKINLAY, A. C. The Econometrics of Financial Markets., $2^{\circ}$ Ed, New Jersey: Princeton U. P., 1997.

CLINCH, G.; MAGLIOLO, J. Market perceptions of reserve disclosures under SFAS $\mathrm{n}^{\circ} 69$. The Accounting Review, v. 67, n. 4, p. 843-861, out, 1992.

CORTESE, C. L.; IRVINE, H. Investigating international accounting standard setting: the black box of IFRS 6. Research in Accounting Regulation, v. 22, p. 87-95. 2010.

COSTA JUNIOR, J. V. Retornos anormais versus performances operacionais anormais de firmas brasileiras envolvidas em fusões e aquisições no período de 2002 a 2006. 2008. 155 f. Tese (Doutorado) - Curso de Ciências Contábeis, Universidade de São Paulo, São Paulo, 2008

DOMINGUES, J. C. A.; RIBEIRO, E. M. S. A relevância das informações contábeis e suplementares na avaliação de petrolíferas mundiais. Revista Base (Administração e Contabilidade) da UNISINOS, v. 13, n. 2, p. 122-137, 2016.

FAMA, E. F. Efficient capital markets: a review of theory and empirical work. The Journal of Finance, v. 25, n. 2, p. 383-417, 1970.

FAMA, E. F. Efficient capital markets: II. The Journal of Finance, v. 46, n. 5, p. 1575-1617, 1991. 
HARRIS, T. S.; OHLSON, J. A. Accounting disclosures and the market's valuation of oil and gas properties. The Accounting Review. 57(4), pp. 651-670, 1987.

HOLTHAUSEN, R. W.; WATTS, R. L. The relevance of the value-relevance literature for financial accounting standard setting. Journal of Accounting and Economics, v. 31, p. 3-75, 2001.

IASB - International Accounting Standards Board. Conceptual Framework for Financial Reporting, 2010.

IUDÍCIBUS, S.; LOPES, A. B. Teoria avançada da contabilidade. São Paulo: Atlas, 2008.

JOHNSEN, T.; PAXSON, D.A.; RIZZUTO, R. J. Are petroleum market values a triumph of economics over accounting? Journal of Business Finance \& Accounting, v. 23, n. 2, p. 243 $261,1996$.

KOTHARI, S. P. Capital markets research in accounting. Journal of Accounting and Economics, v.31, p. 105-231, 2001.

LOPES, A. B.; MARTINS, E. Teoria da contabilidade: uma nova abordagem. São Paulo: Atlas, 2005.

MACEDO, M. A. S.; MACHADO, M. A. V.; MURCIA, F. D.; MACHADO, M. R. Análise do impacto da substituição da DOAR pela DFC: um estudo sob a perspectiva do value relevance. Revista de Contabilidade e Finanças, v. 22, n. 57, p. 299-318, 2011.

MISUND, B.; OSMUNDSEN, P.; ASCHE, F. The value-relevance of accounting figures in the international oil and gas industry - cash flows or accruals? In: Annual North American Conference of the USAEE/IAEE, 25º 2005. Anais ... Denver: IAEE, 2005.

MÜNCH, M. G. et al. Reservas de petróleo e gás: os investidores possuem informação suficiente para suas análises? Congresso Brasileiro de P\&D em Petróleo e gás, Campinas, 2007.

OHLSON, J.A. Earnings, book values, and dividends in equity valuation. Contemporary Accounting Research, v.11, p. 661-687. 1995.

OSMUNDSEN, P.; ASCHE, F.; MISUND, B.; MOHN, K. Valuation of international oil companies. The Energy Journal, v. 27, n. 3, p. 49-64, 2006.

PIMENTA, M.; MARQUES, J. A. V. C; MACEDO, M.A.S. Retornos anormais versus criação de valor e sinergias operacionais de firmas brasileiras envolvidas em combinações de negócios. Pensar Contábil, v. 17, p. 30, 2015.

QUIRIN, J. J.; BERRY, K. T.; O`BRYAN, D. A fundamental analysis approach to oil and gas firm valuation. Journal of Business Finance and Accounting, v. 27, p. 785-820, setembro/outubro, 2000.

RIBEIRO, E.; MENEZES NETO, L.; BONE, R. Reservas de petróleo e gás em modelos de avaliação para empresas petrolíferas. Revista Brasileira de Finanças, v. 9, n. 4, p. 549-569, Rio de Janeiro, dezembro, 2011. 
RICHARDSON, R. J. Pesquisa Social: métodos e técnicas. 3.ed. São Paulo: Atlas, 2012.

SANTOS, O. M.; SILVA, P. D. A. Extractive activities: evidências empíricas ao discussion paper do IASB. Advances in Scientific and Applied Accounting, v. 8, n. 3, p. 273-299, set/dez, 2015.

SANTOS, O. M.; SILVA, P. D. A. Os métodos contábeis dos esforços bem sucedidos capitalização total: um estudo sob a perspectiva do Value Relevance. Enfoque, v. 33, p. 121$138,2014$.

SANTOS, O. M.; SILVA, P. D. A. ; SANTOS, A. Análise das cartas-comentários submetidas em resposta ao discussion paper extractive activities: perspectivas quanto ao futuro do IFRS 6 (CPC 34). Revista Contemporânea de Contabilidade, v. 12, p. 2, 2015.

SPEAR, N. A. The stock market reaction to the reserve quantity disclosures of U.S. oil and gas producers. Contemporary Accounting Research, v. 11, n. 1, p. 381-404, 1994.

TAKAMATSU, R. T., LAMOUNIER, W. M., COLAUTO, R. D. Impactos na divulgação de prejuízos nos retornos de ações de companhias participantes da Bovespa. Revista Universo Contábil, Blumenau, v. 4, n. 1, p. 46-63, jan./mar. 2008.

TEALL, H. D. Information content of Canadian oil and gas companies historic cost earnings and reserves. Contemporary Accounting Research, v. 8, n. 2, 1992.

WATTS, R. L.; ZIMMERMAN, J. L. Positive accounting theory: a ten year perspective. The Accounting Review, v. 65, n. 1, p. $131-156,1990$. 
O IMPACTO DA OCPC 07 SOBRE O TAMANHO E A LEGIBILIDADE DAS NOTAS EXPLICATIVAS DE COMPANHIAS BRASILEIRAS

ANEXO A

\begin{tabular}{|c|c|c|c|c|c|c|}
\hline & Código & Empresa & País sede & Integrada & $\begin{array}{c}\text { Mét } \\
\text { Contab* }\end{array}$ & $\begin{array}{c}\text { Vlr. } \\
\text { mercado } \\
\text { US\$ B** }\end{array}$ \\
\hline 1 & AAV & Advantage Oil \& Gas Ltd & Canadá & Não & SE & 1,20 \\
\hline 2 & APC & Anadarko Petroleum Corporation & EUA & Não & SE & 24,69 \\
\hline 3 & AR & Antero Resources Corporation & EUA & Não & SE & 6,04 \\
\hline 4 & APA & Apache Corporation & EUA & Não & FC & 16,81 \\
\hline 5 & BTE & Baytex Energy Corp & Canadá & Não & $\mathrm{FC}$ & 0,94 \\
\hline 6 & BXE & Bellatrix Exploration Ltd & Canadá & Não & SE & 0,31 \\
\hline 7 & BBG & Bill Barrett Corporation & EUA & Não & SE & $\mathrm{ND}$ \\
\hline 8 & BSM & Black Stone Minerals, L.P. & EUA & Não & SE & 2,76 \\
\hline 9 & BCEI & Bonanza Creek Energy, Inc. & EUA & Não & SE & 0,26 \\
\hline 10 & $\mathrm{BP}$ & BP p.l.c & Reino Unido & Sim & SE & 95,77 \\
\hline 11 & $\mathrm{COG}$ & Cabot Oil \& Gas Corporation & EUA & Não & SE & 7,32 \\
\hline 12 & CRC & California Resources Corporation & EUA & Não & SE & 0,90 \\
\hline 13 & CPE & Callon Petroleum Company & EUA & Não & $\mathrm{FC}$ & 19,52 \\
\hline 14 & CNQ & Canadian Natural Resources Limited & Canadá & Não & SE & 23,90 \\
\hline 15 & CVE & Cenovus Energy Inc & Canadá & Sim & SE & 14,58 \\
\hline 16 & CHK & Chesapeake Energy Corporation & EUA & Não & FC & 2,99 \\
\hline 17 & CVX & Chevron Corporation & EUA & Sim & SE & 169,38 \\
\hline 18 & SNP & China Petroleum \& Chemical Corporation & China & Sim & SE & 72,62 \\
\hline 19 & XEC & Cimarex Energy Co & EUA & Não & FC & 8,48 \\
\hline 20 & CWEI & Clayton Williams Energy, Inc. & EUA & Não & SE & ND \\
\hline 21 & CEO & CNOOC Limited & China & Não & SE & 46,60 \\
\hline 22 & CIE & Cobalt International Energy, Inc. & EUA & Não & SE & ND \\
\hline 23 & CRK & Comstock Resources, Inc. & EUA & Não & SE & 0,09 \\
\hline 24 & $\mathrm{CXO}$ & Concho Resources Inc. & EUA & Não & SE & 11,99 \\
\hline 25 & $\mathrm{COP}$ & ConocoPhillips & EUA & Não & SE & 57,71 \\
\hline 26 & CLR & Continental Resources, Inc. & EUA & Não & SE & 8,57 \\
\hline 27 & CPG & Crescent Point Energy Corporation & Canadá & Não & SE & 8,14 \\
\hline 28 & CRT & Cross Timbers Royalty Trust & EUA & Não & $\mathrm{FC}$ & 0,08 \\
\hline 29 & DNR & Denbury Resources Inc. & EUA & Não & $\mathrm{FC}$ & 0,71 \\
\hline 30 & DVN & Devon Energy Corporation & EUA & Não & FC & 13,38 \\
\hline 31 & ECT & ECA Marcellus Trust I & EUA & Sim & $\mathrm{FC}$ & 0,03 \\
\hline 32 & ECR & Eclipse Resources Corporation & EUA & Não & SE & 0,41 \\
\hline 33 & EC & Ecopetrol S.A. & Colômbia & Sim & SE & 14,41 \\
\hline 34 & ECA & Encana Corporation & Canadá & Não & SE & 5,98 \\
\hline 35 & NDRO & Enduro Royalty Trust & EUA & Não & SE & ND \\
\hline 36 & EGN & Energen Corporation & EUA & Não & SE & ND \\
\hline 37 & ERF & Enerplus Corporation & Canadá & Não & $\mathrm{FC}$ & 0,71 \\
\hline 38 & $\mathrm{E}$ & ENI S.p.A. & Itália & Sim & $\mathrm{FC}$ & 54,15 \\
\hline 39 & EOG & EOG Resources, Inc. & EUA & Não & SE & 38,92 \\
\hline 40 & EPE & EP Energy Corporation & EUA & Não & FC & 1,09 \\
\hline 41 & EQT & EQT Corporation & EUA & Não & $\mathrm{SE}$ & 14,61 \\
\hline 42 & $\mathrm{XCO}$ & EXCO Resources NL & EUA & Não & $\mathrm{FC}$ & ND \\
\hline 43 & XOM & Exxon Mobil Corporation & EUA & Sim & SE & 323,96 \\
\hline 44 & GPRK & Geopark Ltd & Chile & Não & SE & 0,16 \\
\hline 45 & GTE & Gran Tierra Energy Inc & Canadá & Não & $\mathrm{FC}$ & 0,85 \\
\hline 46 & HK & Halcon Resources Corporation & EUA & Não & FC & 0,15 \\
\hline 47 & HNR & Harvest Natural Resources Inc & EUA & Não & SE & ND \\
\hline 48 & HES & Hess Corporation & EUA & Sim & SE & 13,87 \\
\hline 49 & HGT & Hugoton Royalty Trust & EUA & Não & $\mathrm{FC}$ & 0,06 \\
\hline 50 & IMO & Imperial Oil Ltd & Canadá & Sim & SE & 38,21 \\
\hline 51 & JONE & Jones Energy, Inc. & EUA & Não & SE & 0,23 \\
\hline 52 & KOS & Kosmos Energy Ltd. & EUA & Não & SE & 2,00 \\
\hline 53 & LPI & Laredo Petroleum, Inc. & EUA & Não & FC & 1,71 \\
\hline 54 & MRO & Marathon Oil Corporation & EUA & Não & SE & 8,52 \\
\hline 55 & MTDR & Matador Resources Company & EUA & Não & FC & 1,69 \\
\hline 56 & MUR & Murphy Oil Corporation & EUA & Não & SE & 3,86 \\
\hline 57 & MVO & MV Oil Trust & EUA & Não & $\mathrm{FC}$ & 0,06 \\
\hline 58 & NFX & Newfield Exploration Company & EUA & Não & $\mathrm{FC}$ & 5,32 \\
\hline 59 & NBL & Noble Energy Inc. & EUA & Não & SE & 14,12 \\
\hline
\end{tabular}


Raphael da Fonseca - José Augusto Veiga da Costa Marques - Odilanei Morais dos Santos

\begin{tabular}{|c|c|c|c|c|c|c|}
\hline 60 & OAS & Oasis Petroleum Inc. & EUA & Não & SE & 1,03 \\
\hline 61 & OXY & Occidental Petroleum Corporation & EUA & Não & SE & 51,61 \\
\hline 62 & ROYT & Pacific Coast Oil Trust & EUA & Não & FC & 50,93 \\
\hline 63 & PHX & Panhandle Royalty Company & EUA & Não & $\mathrm{FC}$ & 0,27 \\
\hline 64 & $\mathrm{PE}$ & Parsley Energy, Inc. & EUA & Não & SE & 3,11 \\
\hline 65 & PGH & Pengrowth Energy Corporation & Canadá & Não & $\mathrm{FC}$ & 0,40 \\
\hline 66 & PWE & Penn West Petroleum Ltd & Canadá & Não & FC & ND \\
\hline 67 & PBT & Permian Basin Royalty Trust & EUA & Não & FC & 0,24 \\
\hline 68 & PZE & Petrobras Argentina S.A. & Argentina & Sim & SE & ND \\
\hline 69 & PTR & PetroChina Company Limited & China & Sim & $\mathrm{SE}$ & 0,12 \\
\hline 70 & PBR & Petroleo Brasileiro S.A.- Petrobras & Brasil & Sim & SE & 28,00 \\
\hline 71 & PQ & Petroquest Energy Inc & EUA & Não & FC & 18,73 \\
\hline 72 & PXD & Pioneer Natural Resources Company & EUA & Não & SE & 2,37 \\
\hline 73 & QEP & QEP Resources, Inc. & EUA & Sim & SE & 4,17 \\
\hline 74 & RRC & Range Resources Corporation & EUA & Não & SE & 0,07 \\
\hline 75 & REN & Resolute Energy Corporation & EUA & Não & $\mathrm{FC}$ & ND \\
\hline 76 & RICE & Rice Energy Inc. & EUA & Não & SE & ND \\
\hline 77 & RDS.A & Royal Dutch Shell plc & Reino Unido & Sim & SE & 148,05 \\
\hline 78 & SSN & Samson Oil \& Gas Ltd & Austrália & Não & SE & 0,01 \\
\hline 79 & SJT & San Juan Basin Royalty Trust & EUA & Não & $\mathrm{FC}$ & 0,19 \\
\hline 80 & SN & Sanchez Energy Corporation & EUA & Não & $\mathrm{FC}$ & 0,27 \\
\hline 81 & SSL & Sasol Ltd. & África do Sul & Sim & SE & 17,32 \\
\hline 82 & SM & SM Energy Company & EUA & Não & SE & 1,34 \\
\hline 83 & SWN & Southwestern Energy Company & EUA & Não & $\mathrm{FC}$ & 2,77 \\
\hline 84 & STO & Statoil ASA & Noruega & Sim & SE & 44,51 \\
\hline 85 & SGY & Stone Energy Corporation & EUA & Não & $\mathrm{FC}$ & ND \\
\hline 86 & SU & Suncor Energy Inc. & Canadá & Sim & SE & 37,31 \\
\hline 87 & TOT & TotalFinaElf, S.A. & França & Sim & SE & 109,68 \\
\hline 88 & EGY & Vaalco Energy Inc & EUA & Não & SE & 0,09 \\
\hline 89 & VET & Vermilion Energy Inc. & Canadá & Não & SE & 4,21 \\
\hline 90 & VOC & VOC Energy Trust & EUA & Não & $\mathrm{FC}$ & 0,04 \\
\hline 91 & WTI & W\&T Offshore, Inc. & EUA & Não & FC & 0,18 \\
\hline 92 & WLL & Whiting Petroleum Corporation & EUA & Não & SE & 1,93 \\
\hline 93 & WPX & WPX Energy, Inc. & EUA & Não & SE & 1,58 \\
\hline 94 & YPF & YPF Sociedad Anonima & Argentina & Sim & SE & 6,18 \\
\hline \multicolumn{3}{|r|}{ Total } & & & & $1.697,51$ \\
\hline
\end{tabular}

* Método contábil adotado nas demonstrações referentes a 2015;

** Valor de mercado, em bilhões de dólares norte-americanos, em 31/12/2015. 